\title{
Supporting Information \\ Polarization of Gold in Nanopores Leads to Ion Current Rectification
}

Crystal Yang, ${ }^{\# 1}$ Preston Hinkle, ${ }^{\# 2}$ Justin Menestrina, ${ }^{2}$ Ivan V. Vlassiouk, ${ }^{3}$ Zuzanna S. Siwy ${ }^{1,2,4^{*}}$

${ }^{1}$ Department of Chemistry, University of California, Irvine, CA 92697

${ }^{2}$ Department of Physics and Astronomy, University of California, Irvine, CA 92697

${ }^{3}$ Oak Ridge National Laboratory, 1 Bethel Valley Road, Oak Ridge, TN, 37831, United States

${ }^{4}$ Department of Bioengineering, University of California, Irvine, CA 92697, United States

\section{Transmission electron microscopy image of a single nanopore.}

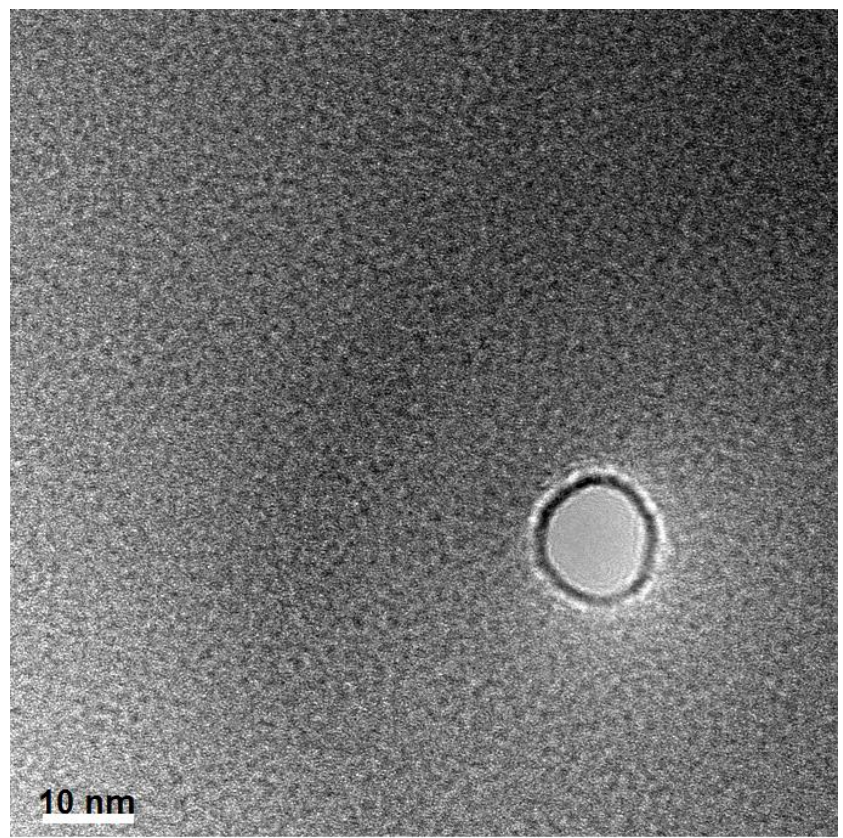

Figure S1. An example image of a single SiN nanopore drilled with e-beam in a transmission electron microscope.

\# These authors contributed equally; ${ }^{\text {C Corresponding Author: zsiwy@uci.edu, Tel. 949-824-8290 }}$ 
II. Examples of ion current through independently prepared SiN-Au nanopores.

(a)
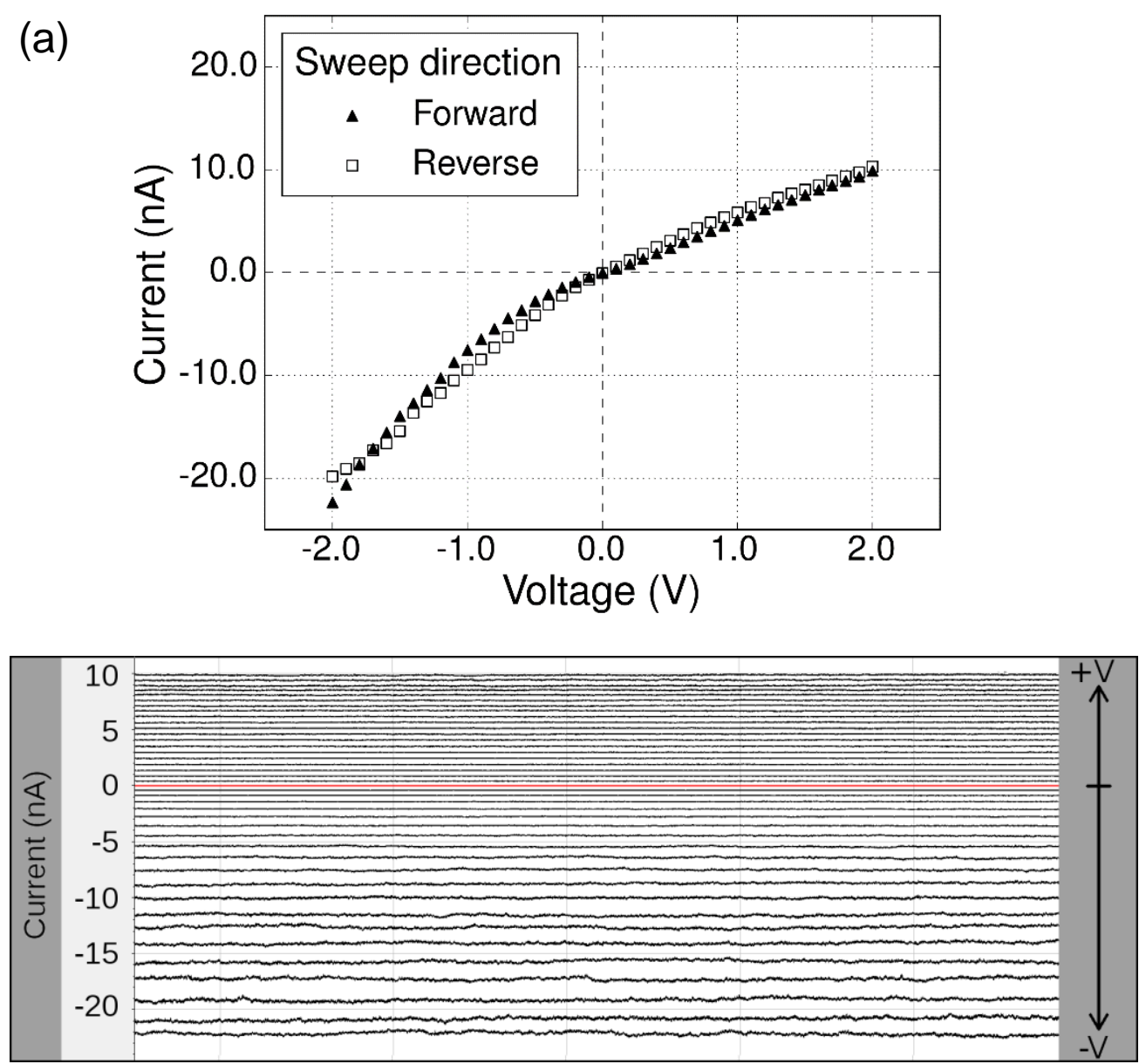
(b)
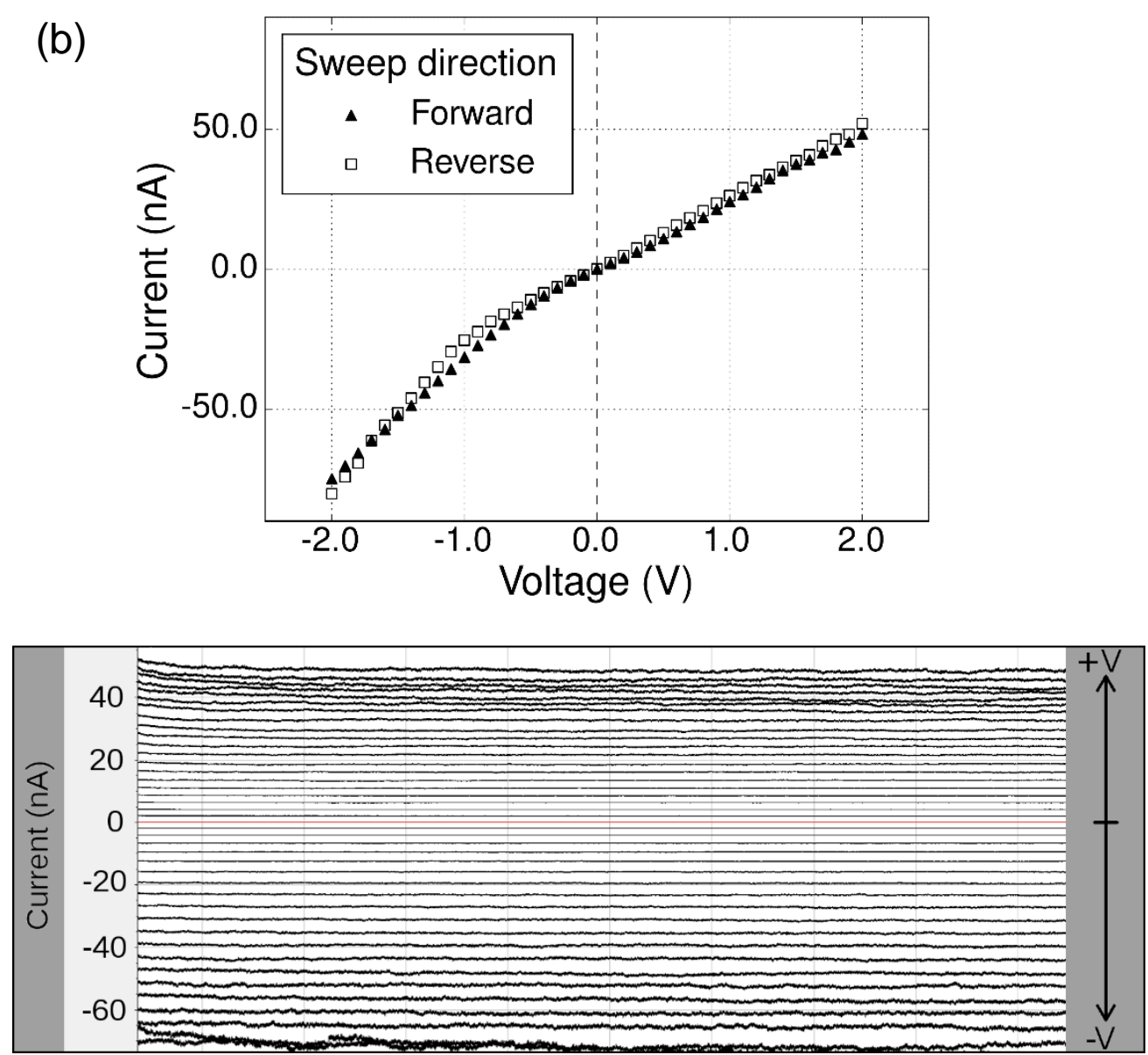

Figure S2. Recordings of ion current through an approximately $9 \mathrm{~nm}$ in diameter SiN nanopore containing a stacked layer of $3 \mathrm{~nm} \mathrm{Cr}$ and $27 \mathrm{~nm}$ Au at one pore entrance. Measurements were done in (a) $100 \mathrm{mM} \mathrm{KF}$ and (b) $500 \mathrm{mM} \mathrm{KF}$. Note the lower rectification in the higher salt concentration. 20 s long time series of ion current are shown; average magnitudes of ion current are shown as I-V curves. 

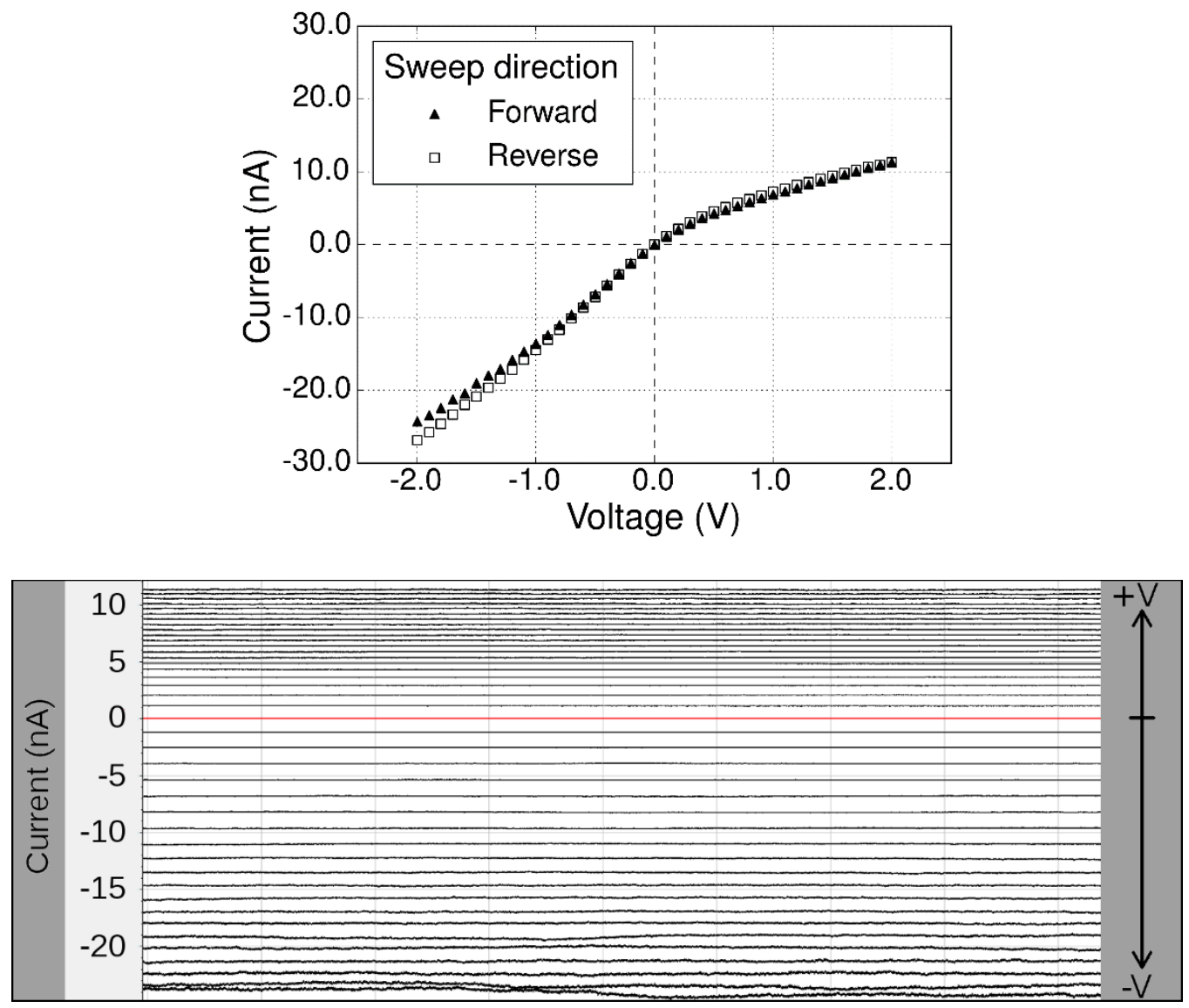

Figure S3. Transport properties of a different nanoporous device than the one shown in Figure S2. $20 \mathrm{~s}$ long time series of ion current is shown. The recordings were performed in $100 \mathrm{mM} \mathrm{KF}$. The pore opening diameter was $13 \mathrm{~nm}$. This pore also contained a $30 \mathrm{~nm}$ $\mathrm{Cr}$, Au layer at one entrance. 


\section{Transport properties of SiN nanopores without Au.}
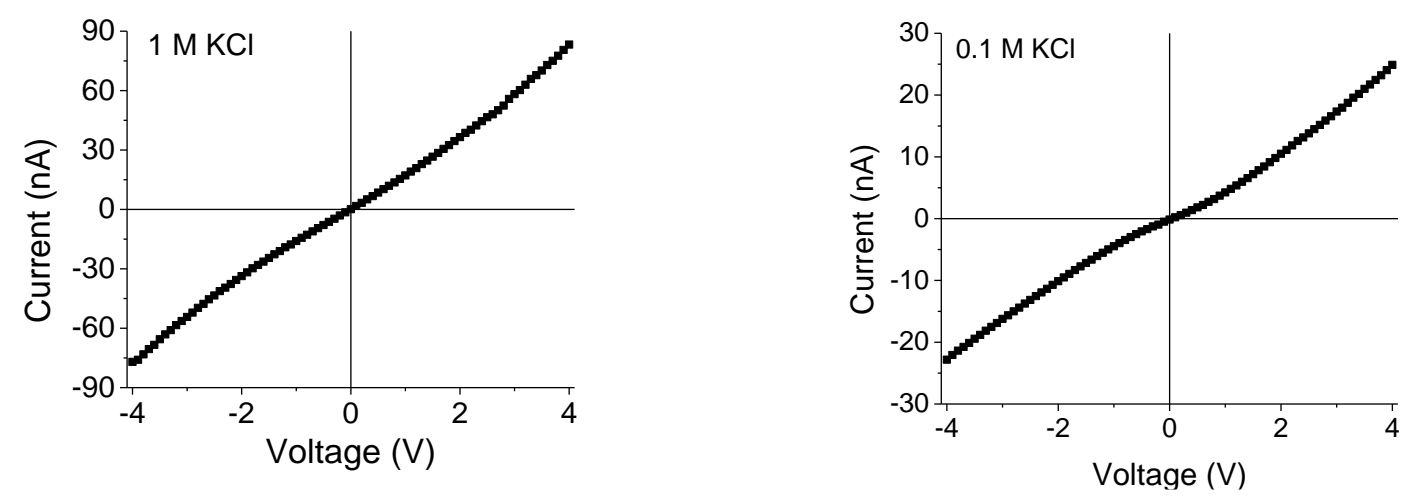

Figure S4. Current-voltage curves through a single $10 \mathrm{~nm}$ in diameter SiN nanopore without deposited Au.

\section{Comparison of nanopores with fluctuating and stable ion current signals.}
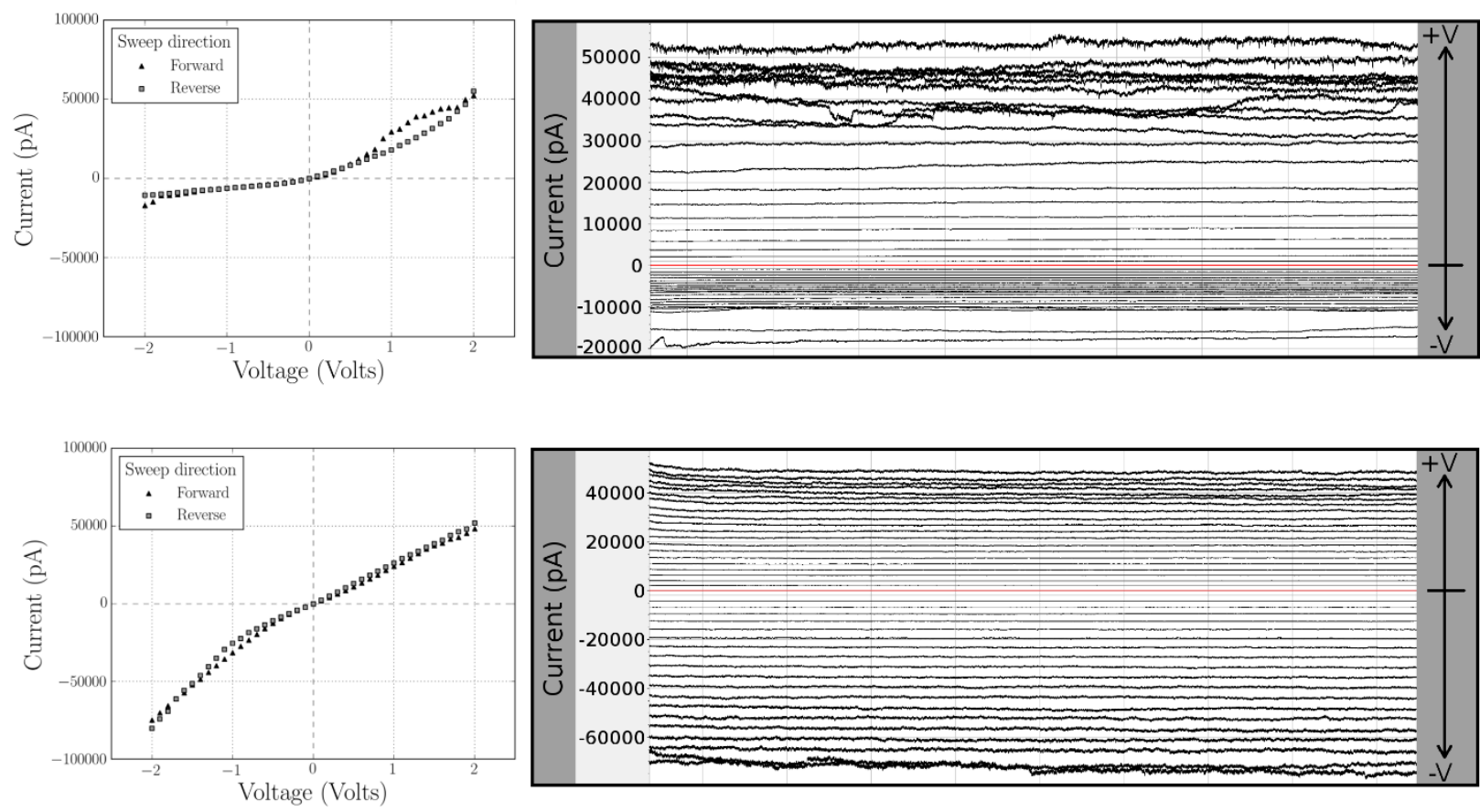

Figure S5. Ion current recordings through a SiN nanopore with Au layer. $20 \mathrm{~s}$ long time series of ion current are shown. The same nanopore first showed fluctuating ion current signal in time in the first sweep, and eventually produced stable ion current signals after two subsequent sweeps. Note that average magnitudes of ion current in time in the two cases predict different rectification behavior of the same nanopore. This is the same pore as in Figure S2, recorded in $500 \mathrm{mM} \mathrm{KF}$. 


\section{Transport properties of SiN-Au nanopores in $\mathrm{KF}$ and $\mathrm{KCl}$.}

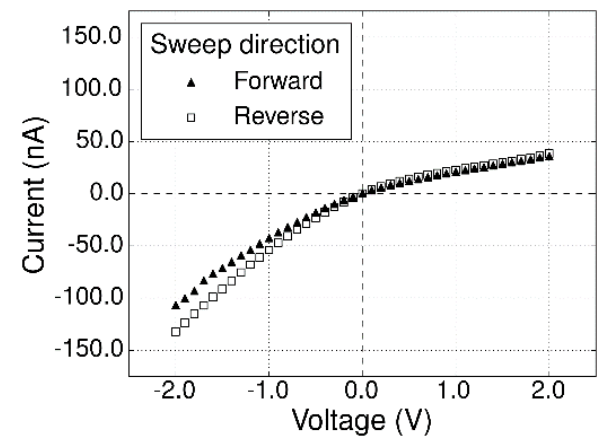

$500 \mathrm{mM} \mathrm{KF}$
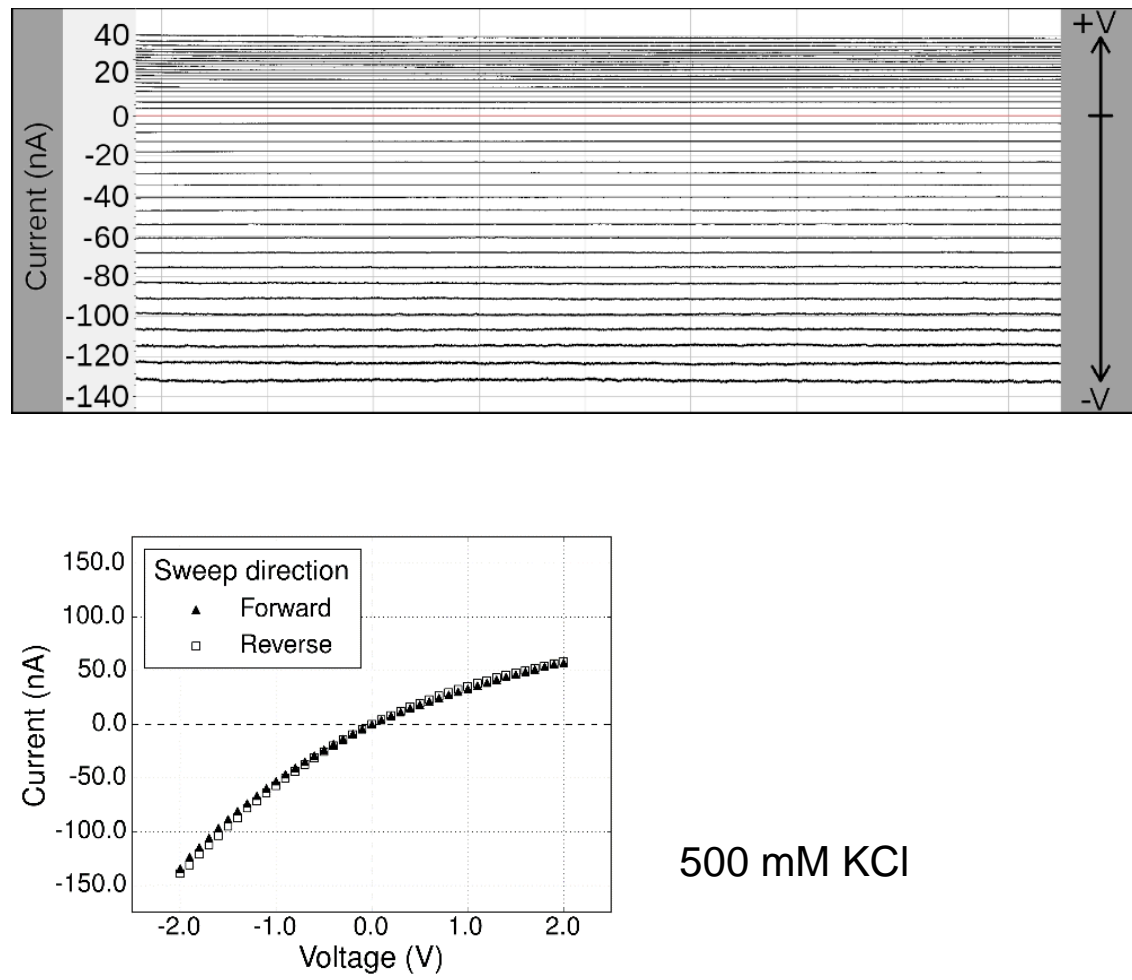

$500 \mathrm{mM} \mathrm{KCl}$

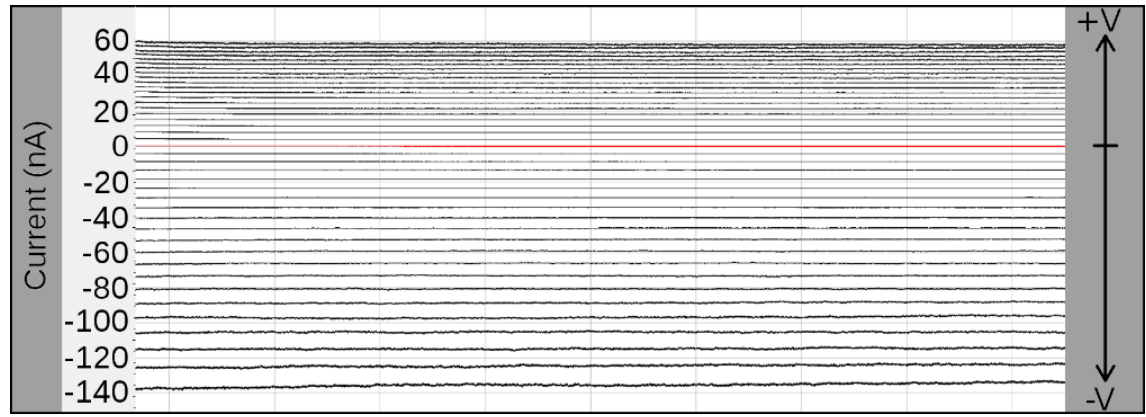

Figure S6. Current-voltage curves and ion current signals through a SiN-Cr,Au nanopore in $500 \mathrm{mM} \mathrm{KF}$ and $500 \mathrm{mM} \mathrm{KCl}$. $20 \mathrm{~s}$ long time series of ion current are shown. The pore had an opening diameter of $\sim 12 \mathrm{~nm}$. 


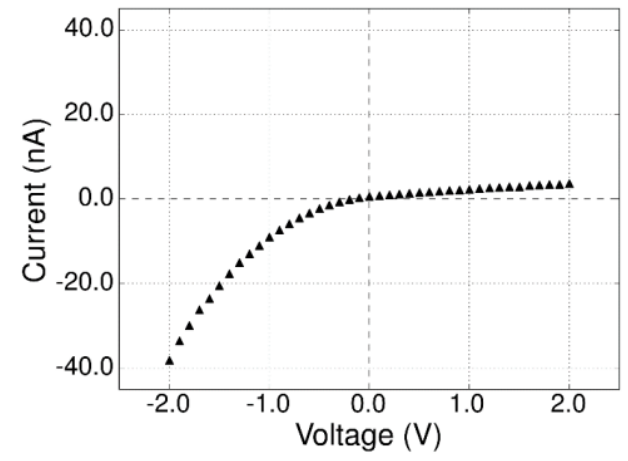

$100 \mathrm{mM} \mathrm{KF}$
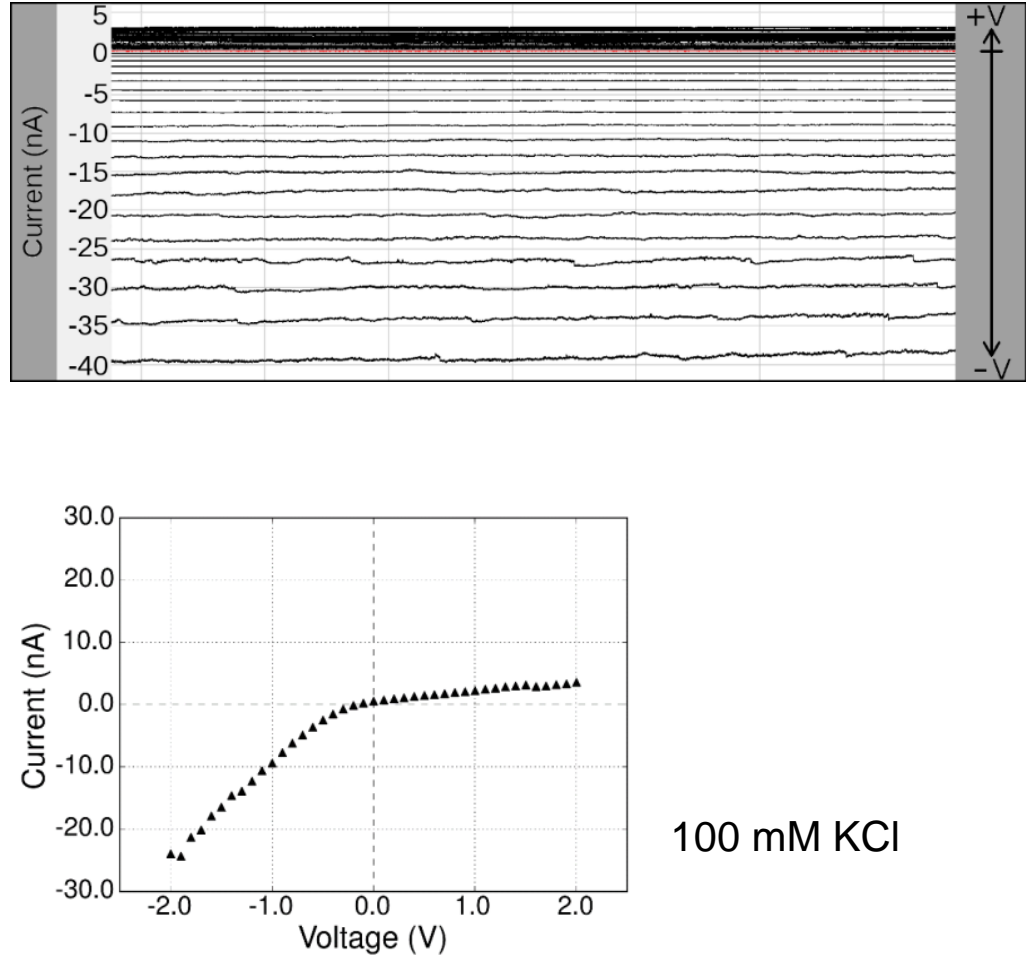

$100 \mathrm{mM} \mathrm{KCl}$

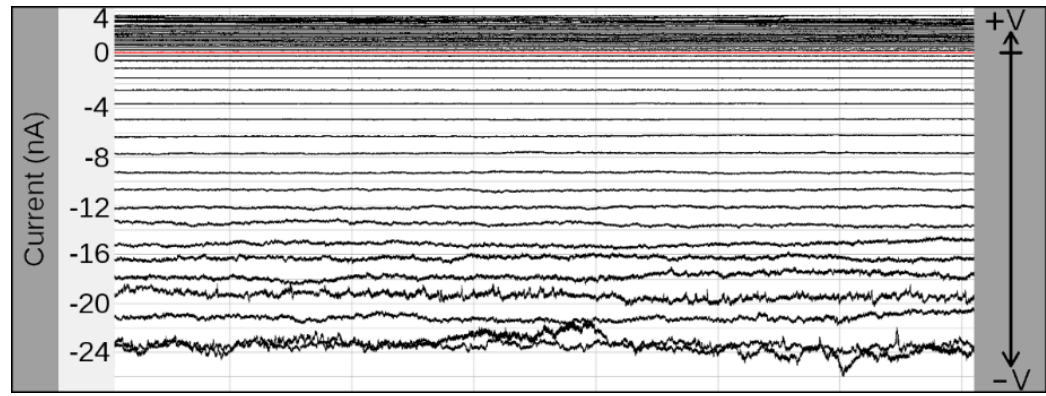

Figure S7. Current-voltage curves and ion current signals through a SiN-Cr,Au nanopore in $100 \mathrm{mM} \mathrm{KF}$ and $100 \mathrm{mM} \mathrm{KCl}$. 20 s long time series of ion current are shown. Opening diameter of this pore was $\sim 12 \mathrm{~nm}$. This is a different nanopore than the one shown in Figure S6. 


\section{Details of Comsol modeling}

The experimental system of SiN-Au nanopore was modelled in a steady-state axiallysymmetric 2-D system containing a two-layer channel with uniform radius, separating two large reservoirs (Figure S8). The silicon nitride surface charge was modelled by a uniform $-0.016 \mathrm{C} / \mathrm{m}^{2}$ surface charge placed on the pore interior and surface extending along the reservoir. The Au layer was implemented as a $15 \mathrm{~nm}$ thick layer stretching along the entire simulated area of one side of the substrate. A floating potential boundary condition within COMSOL's electrostatics module was set on this surface to simulate the physics of the metallic Au. Voltage was applied via a voltage boundary condition on the open boundaries of the reservoir, with the top reservoir's boundaries chosen as the working electrode. Model electrolyte solution was composed of water and two symmetric ions with mobilities chosen to equal the bulk mobility of potassium in water. Ion convection, diffusion, and migration are simulated by the Transport of Diluted Species module, describing the full Poisson-Nernst-Planck (PNP) equations. The open boundaries of the reservoir were held at fixed ion concentration to simulate the bulk solution. To simulate the hydrodynamics in the system (i.e., due to electroosmosis), we used the Laminar Flow module which applies the Navier-Stokes equations under the assumptions of low Reynold's number and solvent incompressibility. Non-slip boundary conditions were applied at every closed boundary. The open boundaries of the reservoir were set as inlets and outlets to allow for transport of water in the system. All simulations shown in the main manuscript were obtained with dielectric constant of the solution of 80 . Figure S9 compares current-voltages curves obtained with dielectric constant of 80 and 53.4 (reported before for 50\%/50\% water/ethanol mixture).

A triangular mesh shape was used for the simulations. To ensure the mesh was fine enough to capture double-layer and other relevant nanoscale physics, the mesh density was constrained at all surfaces to be much smaller than the expected experimental Debye length in $0.1 \mathrm{M} \mathrm{KF}$ solution $(\sim 1 \mathrm{~nm})$. For example, the length scale of the mesh along the pore-entrance is $12.5 \mathrm{pm}$. Furthermore, the solution of the model at the used mesh density was validated by increasing the mesh density and comparing the ionic currents in the pore (Table S1). For mesh densities under the Debye length the obtained values for the ionic current in the pore did not significantly vary from mesh-to-mesh, giving us confidence that the chosen density was appropriate to simulate the relevant physics in fine-detail.

Convergence of the solution was only achieved by applying proper initial conditions at each voltage. Voltage sweeps were run in a manner similar to the method used to obtain IV curves in experiments. First, the model was solved with no applied voltage. Then, the voltage was decremented by $0.1 \mathrm{~V}$ until reaching $-1 \mathrm{~V}$, each step in the sweep using the solution from the previous voltage as initial conditions. At $-1 \mathrm{~V}$, the voltage was ramped up in increments of $0.1 \mathrm{~V}$ until reaching its final measured value of $1 \mathrm{~V}$. The measurements of the electrical current when sweeping down from $0 \mathrm{~V}$ to $-1 \mathrm{~V}$ were 
compared to the same measurements during the sweep up from $-1 \mathrm{~V}$ to $0 \mathrm{~V}$ and found to agree (e.g., the electrical current at $-0.5 \mathrm{~V}$ when using the solutions of the $-0.4 \mathrm{~V}$ and -0.6 $\mathrm{V}$ steps as initial conditions was the same).

Simulation results were exported from COMSOL and analysis performed using scripts written in Python. Plots were generated in Python using the matplotlib plotting package.

Table S1. Simulated current as a function of mesh size, L.

\begin{tabular}{|c|c|c|c|c|}
\hline & $\mathrm{L}=0.026 \mathrm{~nm}$ & $\mathrm{~L}=0.024 \mathrm{~nm}$ & $\mathrm{~L}=0.022 \mathrm{~nm}$ & $\mathrm{~L}=0.020 \mathrm{~nm}$ \\
\hline Voltage (V) & Current $(A)$ & $\%$ Change & $\%$ Change & $\%$ Change \\
\hline-1.0 & -1.29E-09 & $3.10 \mathrm{E}-03$ & $6.20 \mathrm{E}-03$ & 7.76E-03 \\
\hline-0.9 & $-1.19 E-09$ & 3.37E-03 & 5.91E-03 & 7.59E-03 \\
\hline-0.8 & $-1.08 \mathrm{E}-09$ & $2.78 \mathrm{E}-03$ & 5.56E-03 & 6.49E-03 \\
\hline-0.7 & $-9.71 E-10$ & $2.16 \mathrm{E}-03$ & $4.22 E-03$ & $5.46 \mathrm{E}-03$ \\
\hline-0.6 & $-8.61 E-10$ & $-5.81 E-04$ & $-4.65 E-04$ & $-3.48 E-04$ \\
\hline-0.5 & $-7.47 \mathrm{E}-10$ & 9.37E-04 & $2.28 \mathrm{E}-03$ & $2.95 E-03$ \\
\hline-0.4 & $-6.28 E-10$ & $-3.19 E-04$ & $0.00 \mathrm{E}+00$ & 1.59E-04 \\
\hline-0.3 & $-4.99 \mathrm{E}-10$ & $-7.62 \mathrm{E}-03$ & $-1.16 E-02$ & $-1.40 \mathrm{E}-02$ \\
\hline-0.2 & $-3.51 \mathrm{E}-10$ & $-7.98 \mathrm{E}-03$ & $-1.25 \mathrm{E}-02$ & $-1.54 \mathrm{E}-02$ \\
\hline-0.1 & $-1.79 E-10$ & $-9.50 \mathrm{E}-03$ & $2.72 \mathrm{E}-01$ & $2.46 \mathrm{E}-01$ \\
\hline 0.0 & $9.04 \mathrm{E}-14$ & $-1.23 E+01$ & $-2.21 E+01$ & $-2.98 \mathrm{E}+01$ \\
\hline 0.1 & $1.40 \mathrm{E}-10$ & $-7.17 \mathrm{E}-04$ & $-1.43 E-03$ & $-1.43 E-03$ \\
\hline 0.2 & $2.07 \mathrm{E}-10$ & $-5.81 E-03$ & $-1.06 \mathrm{E}-02$ & $-1.45 \mathrm{E}-02$ \\
\hline 0.3 & $2.26 \mathrm{E}-10$ & $-6.64 \mathrm{E}-03$ & $-1.28 \mathrm{E}-02$ & $-1.73 \mathrm{E}-02$ \\
\hline 0.4 & $2.35 \mathrm{E}-10$ & $-7.24 \mathrm{E}-03$ & $-1.32 \mathrm{E}-02$ & $-1.79 \mathrm{E}-02$ \\
\hline 0.5 & $2.41 \mathrm{E}-10$ & $-7.47 \mathrm{E}-03$ & $-1.37 \mathrm{E}-02$ & $-1.83 \mathrm{E}-02$ \\
\hline 0.6 & $2.46 \mathrm{E}-10$ & $-7.32 \mathrm{E}-03$ & $-1.38 E-02$ & $-1.87 \mathrm{E}-02$ \\
\hline 0.7 & $2.50 \mathrm{E}-10$ & $-7.20 \mathrm{E}-03$ & $-1.36 \mathrm{E}-02$ & $-1.84 \mathrm{E}-02$ \\
\hline 0.8 & $2.54 \mathrm{E}-10$ & $-7.09 E-03$ & $-1.34 \mathrm{E}-02$ & $-1.85 E-02$ \\
\hline 0.9 & $2.57 \mathrm{E}-10$ & $-7.39 E-03$ & $-1.40 \mathrm{E}-02$ & $-1.91 \mathrm{E}-02$ \\
\hline 1.0 & $2.60 \mathrm{E}-10$ & $-7.69 \mathrm{E}-03$ & $-1.38 \mathrm{E}-02$ & $-1.88 \mathrm{E}-02$ \\
\hline
\end{tabular}

Table S1. Simulations were performed iteratively to test the stability of the solutions with respect to a change in mesh density. Columns 1 and 2 in the Table show the currentvoltage (IV) data at the mesh density, L, used for all simulations in the main text. The header row contains the average lengths of mesh elements at the nanopore boundaries for different mesh densities. Columns 3,4 , and 5 show the relative percentage change $\Delta \mathrm{l} / \mathrm{I}^{\star} 100 \%$ of the current measurements as the mesh length/density was decreased/increased. Notice that the largest percentage change is at 0 volts, when the current is negligibly small in all cases. 


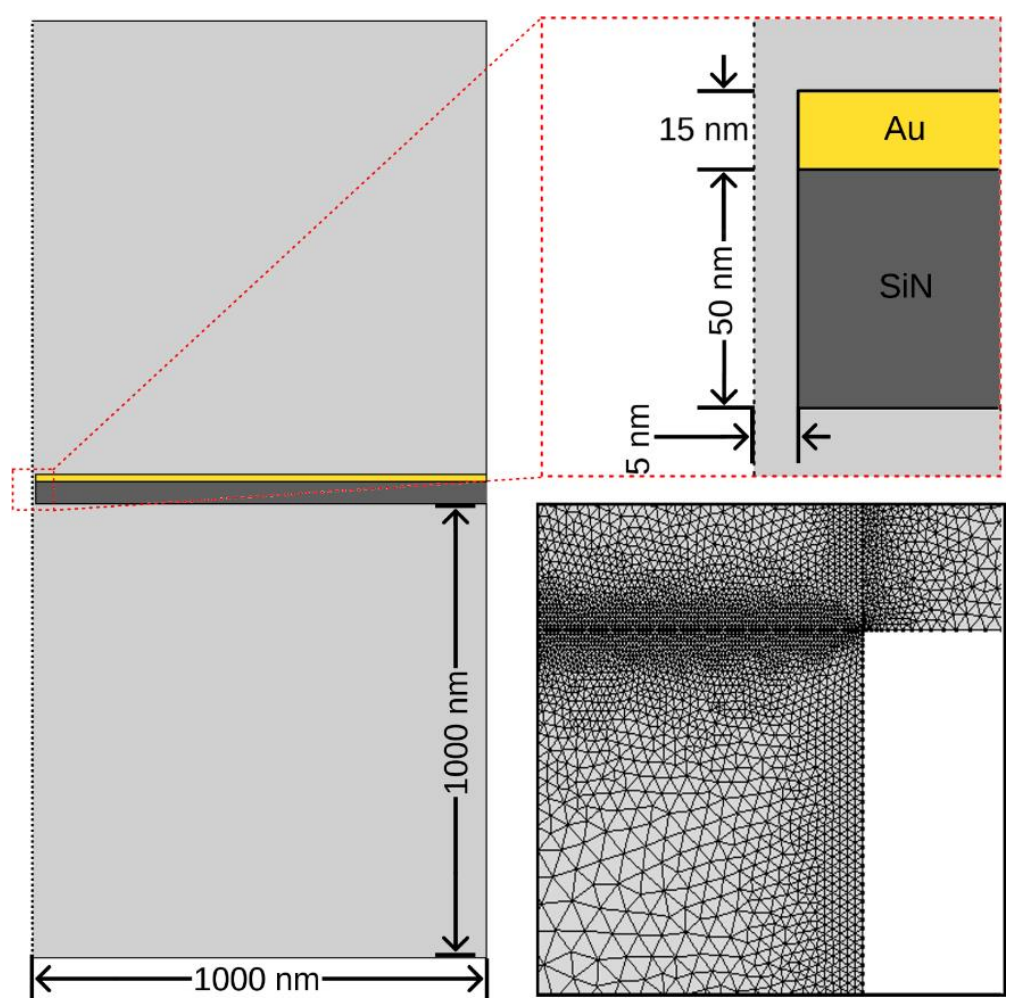

Figure S8. Scheme of the nanopore system modeled in Comsol. 
VII. Additional results of numerical modeling.

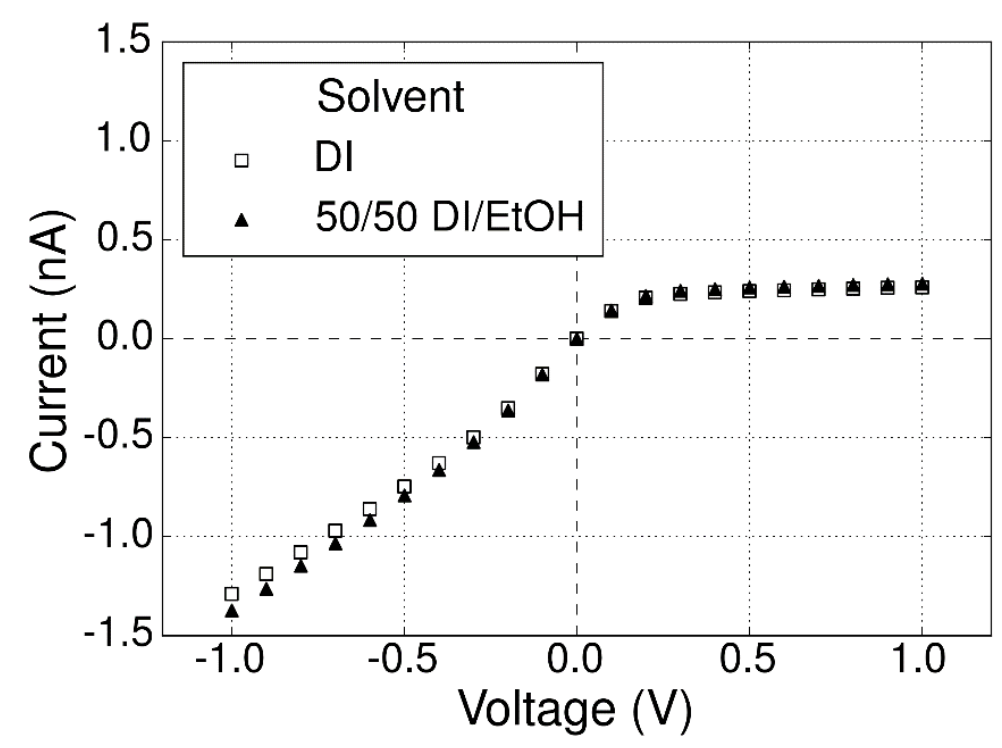

Figure S9. Current-voltage for a nanoporous structure as shown in Figure S8 for two values of dielectric constant, 80 (water), and 53.4 (water/ethanol mixture). $100 \mathrm{mM} \mathrm{KF}$ was used as the bulk electrolyte.

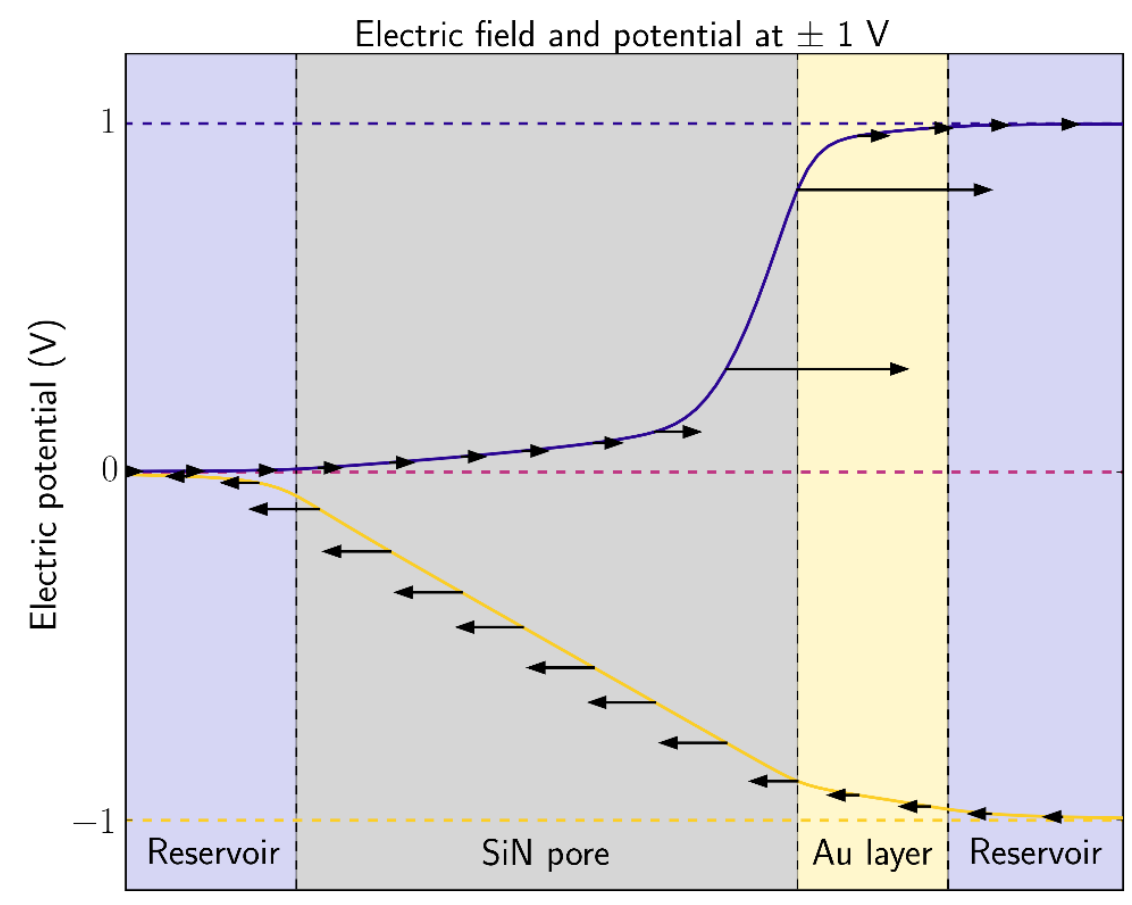

Figure S10. Distribution of electric potential and electric field for two transmembrane potentials $-1 \mathrm{~V}$ and $+1 \mathrm{~V}$. Note nearly zero electric field in the region with Au layer and large potential drop across the depletion zone created at $+1 \mathrm{~V}$. The same system as in Figures 3, S8 was modeled in $100 \mathrm{mM} \mathrm{KF.}$ 


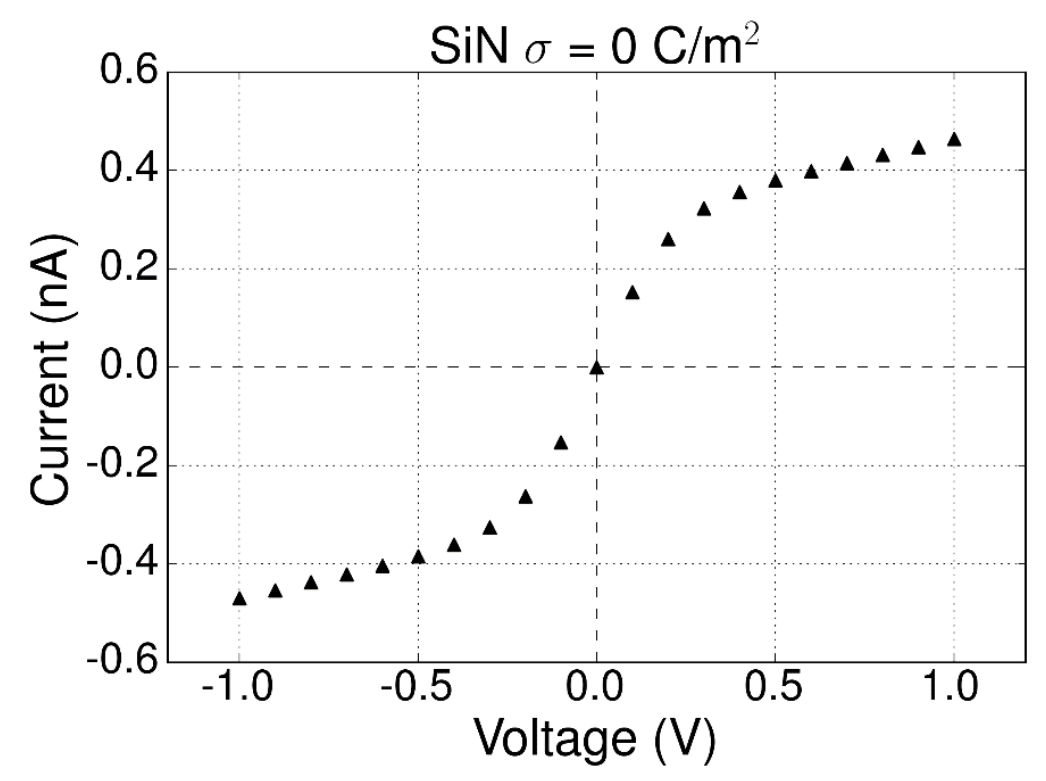

Figure S11. Current-voltage curve predicted for the same system as shown in Figure S8 after removing surface charges from the silicon nitride nanopore at $100 \mathrm{mM} \mathrm{KF}$. The current saturates at higher voltages due to limiting access of ions through the resistiveelement of the silicon nitride nanopore. 